Article

\title{
Immediate Effects of an Inverted Body Position on Energy Expenditure and Blood Lactate Removal after Intense Running
}

\author{
Moo Sung Kim ${ }^{1}$ and Jihong Park ${ }^{2, *(1)}$ \\ 1 Athletic Training Laboratory, Department of Physical Education, Graduate School, Kyung Hee University, \\ Yongin 17104, Korea; kms_ss@khu.ac.kr \\ 2 Athletic Training Laboratory, Department of Sports Medicine, Kyung Hee University, Yongin 17104, Korea \\ * Correspondence: jihong.park@khu.ac.kr; Tel.: +82-31-201-2721
}

Received: 5 September 2020; Accepted: 21 September 2020; Published: 23 September 2020

\begin{abstract}
We compared the immediate effects of a cool-down strategy including an inverted body position (IBP: continuous 30-s alternations of supine and IBP) after a short period of an intense treadmill run with active (walking) and passive (seated) methods. Fifteen healthy subjects (22 years, $172 \mathrm{~cm}, 67 \mathrm{~kg}$ ) completed three cool-down conditions (in a counterbalanced order) followed by a 5-min static stretch on three separate days. Heart rate, energy expenditure, blood lactate concentration, fatigue perception, and circumference of thighs and calves were recorded at pre- and post-run at 0,5 , 10,20 , and $30 \mathrm{~min}$. At $5 \mathrm{~min}$ post-run, subjects performing the IBP condition showed (1) a $22 \%$ slower heart rate $(p<0.0001, \mathrm{ES}=2.52)$ and $14 \%$ lower energy expenditure $(p=0.01, \mathrm{ES}=0.48)$ than in the active condition, and (2) a $23 \%$ lower blood lactate than in the passive condition $(p=0.001, \mathrm{ES}=0.82)$. Fatigue perception and circumferences of thighs and calves did not differ between the conditions at any time point $\left(\mathrm{F}_{10,238}<0.96, p<0.99\right.$ for all tests). IBP appears to produce an effect similar to that of an active cool-down in blood lactate removal with less energy expenditure. This cool-down strategy is recommended for tournament sporting events with short breaks between matches, such as Taekwondo, Judo, and wrestling.
\end{abstract}

Keywords: cool-down strategy; heart rate; fatigue perception

\section{Introduction}

Progressive overload is an essential principle in developing physical fitness, and it often requires fatigue-inducing training [1]. Fatigue is defined as a physiological (and psychological) constraint that results in failure to maintain a certain amount or intensity of voluntary muscle contractions [2]. By overloading exercise-induced fatigue, athletes may experience a temporary (e.g., a few days) performance reduction, referred to as functional overreaching [3]. Nonfunctional overreaching is also considered as the normal process of training adaptation, although it may take a longer time (e.g., a few weeks) to restore function [4]. Overtraining results in performance decrease with persistent physical and/or psychological fatigue for an extended period of time (e.g., a few months) [5]. While athletes and coaches seek optimal training adaptations, inadequate physiological (and psychological) recovery between training sessions can lead to overtraining [6]. Therefore, cool-down strategies to balance training stimulation and physical recovery are just as important as the training program.

Since "active recovery", defined as submaximal exercise or movement immediately following a training session, was first introduced in 1975 [7], its relative superiority over passive recovery has been reported in many studies [8-11]. Specifically, faster decreases of blood lactate [9], intramuscular pH level (due to reduced $\mathrm{H+}$ ) [12], and oxyhemoglobin [13] as well as faster phosphocreatine resynthesis [14] 
are known advantages although the most effective working intensity remains controversial $[9,15]$. Enhancement of oxidation due to a higher rate or volume of blood flow to the working muscles [15] enhances the lactic acid removal [16] and prevents $\mathrm{H}+$ release [17], which allows faster recovery from exercise-induced fatigue. Because of the increase in blood flow, practicing active recovery is preferred, especially when multiple exercise bouts are performed.

If the rate or volume of blood flow is an important causal factor, an inverted body position (IBP) might expedite the recovery process. This gravity-independent position (elevation of the lower body) decreases vascular hydrostatic pressure, resulting in increased venous return and lymphatic drainage [18]. According to the Frank-Starling mechanism [19], an increased venous return increases myocardial stretch (preload), which results in increased stroke volume and cardiac output [20]. Therefore, IBP activity could increase peripheral circulation in the lower extremities and enhance the process of physiological recovery. Previously, a position of head-down tilt at $15^{\circ}$ was shown to increase stroke volume, mean arterial pressure, and cutaneous vascular conductance [21,22]. Another study [23] used the same position for $5 \mathrm{~min}$ and reported a $36 \%$ increase in tibial microvascular flow. Although an acute increase of cardiovascular function from holding a head-down tilt position is evident [21-23], changes of blood lactate removal and fatigue perception have not been evaluated.

Hence, the primary purpose of this study was to examine how a 10-min cool-down protocol containing IBP affects physiological and psychological recovery after intense running compared to the same duration of active (walking) and passive (seated) cool-down strategies. Since the effects of increasing blood flow were achieved on the $15^{\circ}$ head-down tilt [21-23], our IBP protocol had a maximal inclination (up to $90^{\circ}$ ) in expectation of the greatest effects of circulation of blood and body fluids [18]. Considering results from previous head-down tilt studies [21-23], the effects of elevation [18], and the Frank-Starling mechanism theory [19], we hypothesized that the lactate removal rate at the end of IBP would be greater than that of passive recovery at the same time point. Due to more voluntary muscle contractions and movements, we further expected higher values of heart rate and energy expenditure in the active recovery condition than in the IBP and passive recovery conditions.

\section{Materials and Methods}

\subsection{Experimental Design}

We used a three (condition) $\times$ six (time) single-blinded cross-over design with repeated measures of time. To objectively increase exercise-induced blood lactate, a treadmill run was implemented. In this approach, we assumed that heart rate increase by exercise correlates linearly with the amount of blood lactate. To test the condition effect, dependent measurements among the conditions were compared at each time point. Each condition had a 10-min cool-down activity that consisted of $5 \mathrm{~min}$ of IBP, walking on the treadmill or sitting on a chair, and another 5 min of static stretching (same activity for each condition). Therefore, the post-run 5-min time point reflected the acute effect of the IBP whereas the post-run 20- and 30-min time points corresponded to the combined effect of IBP and stretching. The temperature and relative humidity in the laboratory were maintained at $25^{\circ} \mathrm{C}$ and $50 \%$ during the data collection period. One researcher guided the treadmill run and conducted the measurements while being blinded to the cool-down condition by leaving the laboratory while another researcher conducted the cool-down protocol. The study was approved by the Institutional Review Board and was conducted in accordance with the Declaration of Helsinki.

\subsection{Subjects}

Fifteen healthy active adults ( 5 females: $20.4 \pm 0.6$ years, $161.4 \pm 3.3 \mathrm{~cm}, 57.8 \pm 4.2 \mathrm{~kg}$; 10 males: $22.9 \pm 0.9$ years, $176.5 \pm 1.9 \mathrm{~cm}, 72.1 \pm 0.7 \mathrm{~kg}$ ) who were participating in club sports (>240 $\mathrm{min} /$ week) were recruited for this study. Subjects had no history of lower-extremity surgery and were free from musculoskeletal injury within the last six months. Subjects with current lower-extremity 
musculoskeletal pain, anemia, diabetes, or cardiovascular disease were excluded. Prior to participation, all subjects gave informed consent, as approved by the University's Institutional Review Board.

\subsection{Procedures}

Each subject visited the laboratory three times (with a week wash-out period) on separate days at the same time of day (Figure 1).

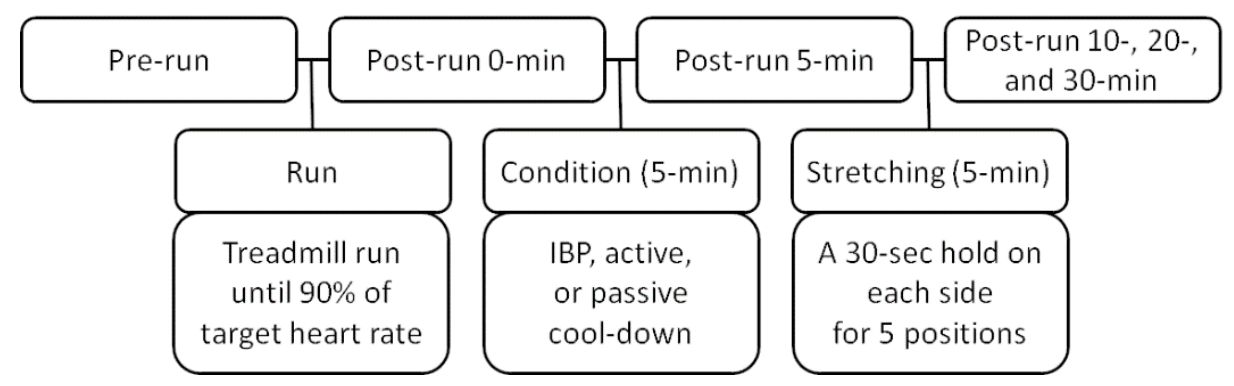

Figure 1. Testing procedures, IBP: inverted body position. Heart rate, energy expenditure, fatigue perception, circumference of lower-extremity, and blood lactate were recorded at each measurement time.

Upon arrival at the laboratory for the first time, subjects read and signed the informed consent form. At each visit, subjects were fitted with a heart rate monitor, and asked to lie down on a treatment table for a 10-min rest to achieve cardiovascular stability before measuring their resting heart rate.

Pre-run measurements were recorded in the order of heart rate, energy expenditure, fatigue perception, circumference of the thighs and calves, and blood lactate (measurements were recorded in the same order at all other time points). Subjects then performed an exercise protocol on the treadmill (Jog Forma, Technogym S.p.A, Gambettola, Italy) where the run began at $4 \mathrm{~km} / \mathrm{h}$ without treadmill inclination and the speed and inclination increased by $1 \mathrm{~km} / \mathrm{h}$ and $0.5 \%$ every minute. The exercise protocol was ended when the subjects reached the target heart rate $(90 \%$ of the maximal heart rate calculated using the Karvonen formula) [24]. The post-run 0-min measurements were recorded immediately. After a set of measurements, the researcher left the laboratory and a different researcher came into the laboratory to guide the cool-down conditions.

Subjects executed the three cool-down conditions (IBP, active, and passive) in a counterbalanced order. For the IBP condition, subjects performed five sets of continuous alternating positions on the inversion table. Each set was defined as a position change from $\mathrm{A}$ to $\mathrm{B}$ for $30 \mathrm{~s}$ (Figure 2A,B) followed by a position change from $B$ to $A$ (Figure 2A,B). The duration of inversion was determined to prevent discomfort due to increased intracranial pressure [25]. To change positions, the researcher asked a subject to press a button on the inversion table. For the active condition, subjects walked on the treadmill at speeds of 5 and $6 \mathrm{~km} / \mathrm{h}$ for females and males, respectively, for $5 \mathrm{~min}$. The walking treadmill speed was determined in our pilot study where we wanted it to be neither too fast (to avoid additional fatigue) nor too slow (no effect on active recovery). For the passive condition, subjects remained seated on a chair for $5 \mathrm{~min}$. After the next set of measurements (post-run $5 \mathrm{~min}$ ), a 5 -min static stretch of the hip adductors, extensors, abductors, and flexors, and knee extensors with a 30-s hold on each side (the same protocol was applied for each condition) was performed. After completion of the static stretch, the post-run 10-, 20-, and 30-min measurements were recorded. 

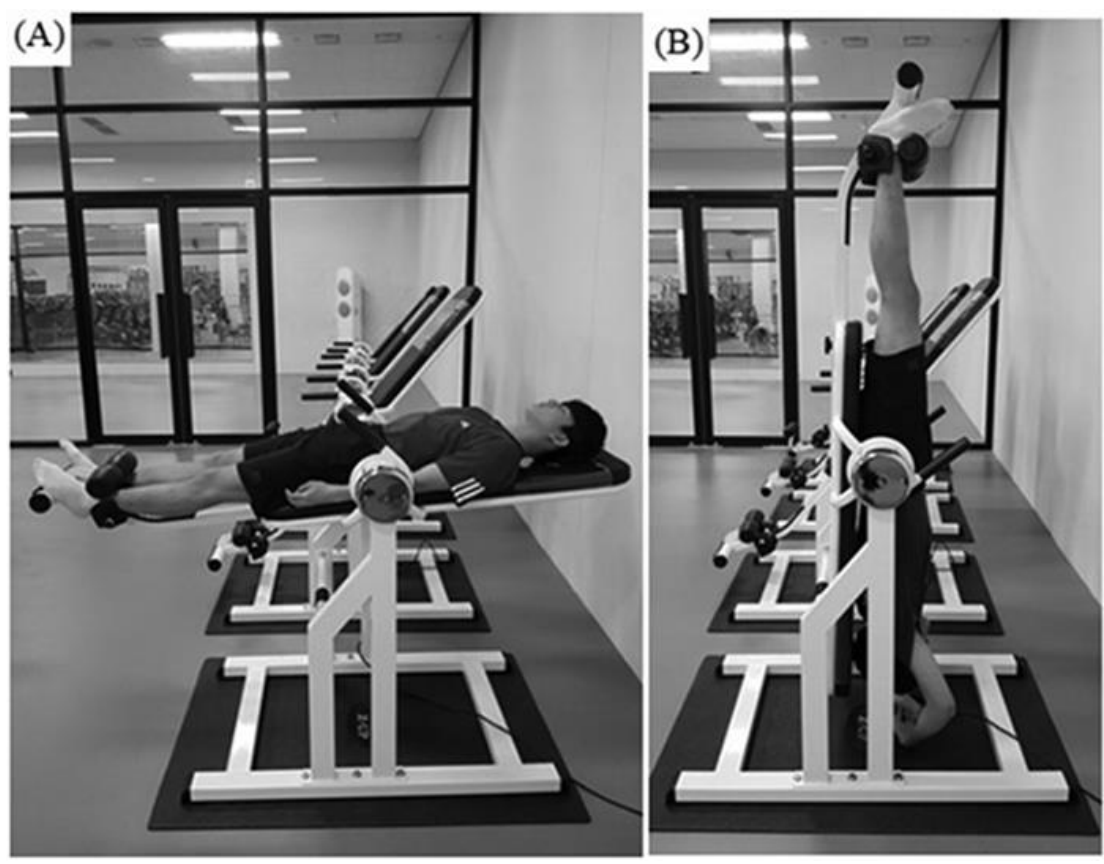

Figure 2. The inverted body position, once subjects moved from (A) a supine position to (B) the IBP, $30 \mathrm{~s}$ were counted and then they were returned to the starting position (A). It took $17 \mathrm{~s}$ to move from position A to B or vice versa. Subjects then spent about $13 \mathrm{~s}$ in the IBP (B) before returning to position (A).

\subsection{Measurements}

The total running time, average treadmill speed, and inclination were recorded for each subject during each treadmill run.

For the blood lactate measurements, a finger-pricking lancet needle (26 G, Lancets, Moa, Korea) was administered to collect $0.7 \mu \mathrm{L}$ blood samples on lactate test strips (Lactate Plus Lactate Test Strips, Nova Biomedical, Waltham, MA, USA). The strips were then inserted into a lactate meter (Lactate Plus, Nova Biomedical, USA) for analysis. The blood lactate analysis using this device was previously validated [26].

To measure heart rate and energy expenditure, the subjects wore a heart rate monitor consisting of a Polar M400 GPS watch on their wrist and a Polar H7 strap on their chests throughout the experiment (Polar Electro Oy, Kempele, Finland). After the device was wirelessly connected to the mobile application (Polar Beat), the subject's age, sex, height, and mass were entered. All data recorded throughout the experiment were downloaded from a website (http://flow.polar.com).

The perception of subjective fatigue level was quantified using a modified 10-cm visual analogue scale $[27,28]$ with the terms "unfatigued" and "fatigued" at each end. Subjects were asked to mark their fatigue level at each measurement time.

Using a tape measure, the circumferences of the thighs and calves were recorded (to the nearest $0.1 \mathrm{~cm}$ ) at the midpoint between the anterior superior iliac spine and the superior pole of the patella and the thickest circumference on the triceps surae, respectively. Both sides were recorded each time (left side first).

\subsection{Statistical Analyses}

Our sample size was calculated based on a pilot study conducted in our laboratory. We expected a mean difference in blood lactate concentration of $3 \mathrm{mmol} / \mathrm{L}$ with a standard deviation of $3.5 \mathrm{mmol} / \mathrm{L}$ (an effect size of 0.86 ). These calculations estimated that 14 individuals would be necessary in each 
condition (an alpha of 0.05 and a beta of 0.2 ). This calculation was supported by a similar previous study $(n=14)$ that reported a difference of $3.17 \mathrm{mmol} / \mathrm{L}$ [10].

Descriptive data (means and $95 \%$ confidence intervals) were calculated and checked for normality using the Shapiro-Wilk test. To test condition effects over time, a mixed model analysis of variance (random variable: subjects; fixed variables: condition and time) and Tukey's test were performed on each dependent measurement. To determine practical significance, Cohen's d effect size [29] was also calculated when statistical significance was found. To test for a correlation between the blood lactate concentration and fatigue perception, Pearson's correlation coefficient was calculated. SAS software (SAS 9.3, Institute Inc., Cary, NC, USA) was used for all tests $(p<0.05)$.

\section{Results}

The mean $\pm 95 \%$ confidence interval total running time was $7 \mathrm{~min}$ and $39 \mathrm{~s} \pm 46 \mathrm{~s}$ at a treadmill speed of $7.3 \pm 0.4 \mathrm{~km} / \mathrm{h}$ and an inclination of $1.7 \pm 0.2 \%$. The mean treadmill speed and inclination at the end of each run were $11.1 \pm 0.8 \mathrm{~km} / \mathrm{h}$ and $3.6 \pm 0.4 \%$, respectively.

The blood lactate concentration was different among the three conditions at post-run 5 and $10 \mathrm{~min}$ (condition $\times$ time interaction: $\mathrm{F}_{10,238}=3.04, p=0.001$; condition effect: $\mathrm{F}_{2,238}=12.38, p<0.0001$; Table 1). Specifically, the IBP condition $(6.7 \mathrm{mmol} / \mathrm{L}, 23 \%, p=0.001, \mathrm{ES}=0.82)$ and the active condition $(6.9 \mathrm{mmol} / \mathrm{L}, 20 \%, p=0.01, \mathrm{ES}=0.75)$ showed lower blood lactate values than the passive condition $(8.6 \mathrm{mmol} / \mathrm{L})$ at post-run $5 \mathrm{~min}$. At post-run $10 \mathrm{~min}$, the active condition showed lower blood lactate values than the passive condition ( 4.4 vs. $6.0 \mathrm{mmol} / \mathrm{L}, 27 \%, p=0.02$, $\mathrm{ES}=0.90)$. Regardless of the condition (time effect: $\mathrm{F}_{5,238}=314.95, p<0.0001$ ), the blood lactate values decreased gradually after running and they did not return to the pre-run level $(1.3 \mathrm{mmol} / \mathrm{L})$ at the end of the experiment (post-run 30-min: $3.1 \mathrm{mmol} / \mathrm{L}, p<0.0001$, ES = 2.41; Figure 3A).
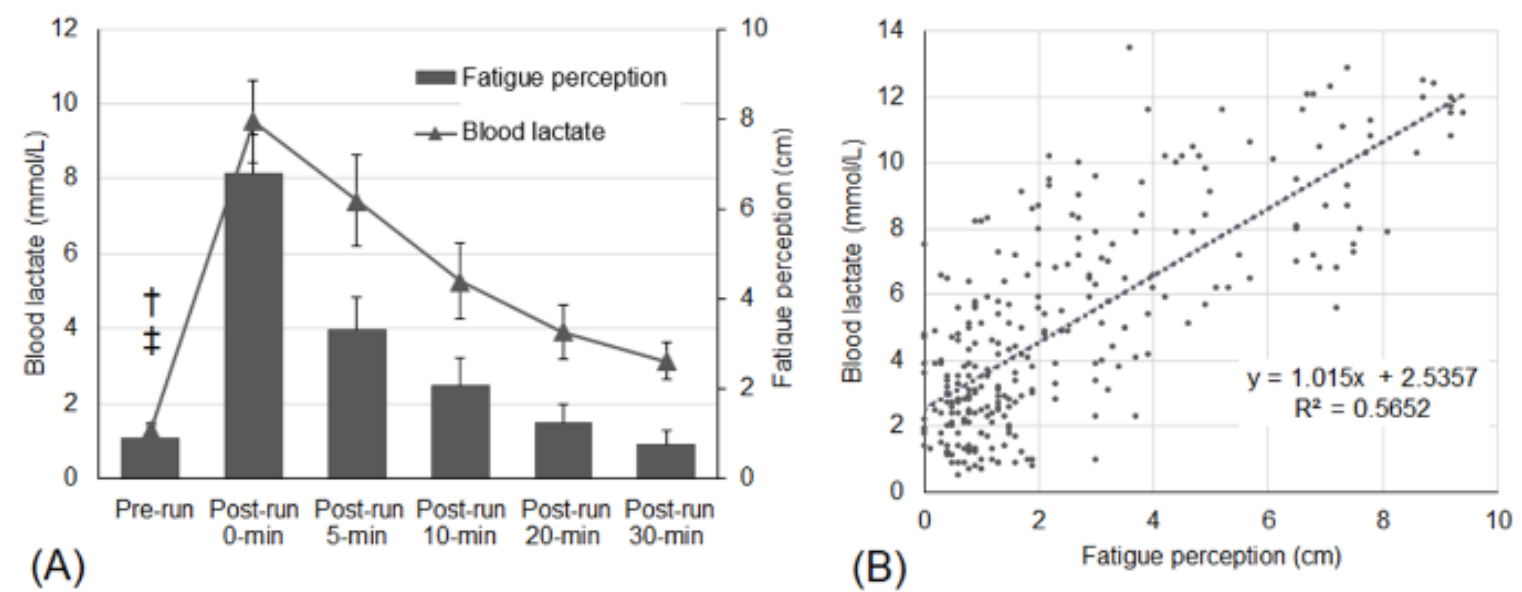

Figure 3. (A) Changes in blood lactate and fatigue perception regardless of conditions. Error bars are upper and lower limits of $95 \%$ confidence intervals. + Different from other time points in blood lactate $(p<0.0001)$. $\ddagger$ Different from post-run 0,5 , and $10 \mathrm{~min}$ in fatigue perception $(p<0.0001)$. (B) Correlation between blood lactate and fatigue perception. There is a high correlation $(r=0.75)$ between blood lactate and fatigue perception.

The heart rate values differed between the conditions at each time point (condition $\times$ time interaction: $\mathrm{F}_{10,238}=8.39, p<0.0001$; condition effect: $\mathrm{F}_{2,238}=17.61, p<0.0001$; time effect: $\mathrm{F}_{5,238}=$ $1243.89, p<0.0001$; Table 1). The IBP condition ( $96 \mathrm{bpm}, 22 \%, p<0.0001, \mathrm{ES}=2.52$ ) and the passive condition $(103 \mathrm{bpm}, 17 \%, p=0.002$, $\mathrm{ES}=1.92)$ resulted in lower heart rate values than the active condition (123 bpm) at post-run $5 \mathrm{~min}$.

Energy expenditure among the three cool-down conditions at each time point did not differ (no condition $\times$ time interaction: $\mathrm{F}_{10,238}=1.65, p=0.09$; time effect: $\mathrm{F}_{5,238}=224.40, p<0.0001$; Table 1). 
However, the total energy expenditure between the conditions was different (condition effect: $F_{2,238}$ $=4.81, p=0.01$ ) in that subjects in the active condition had a $14 \%$ higher total energy expenditure compared to the IBP condition ( 219 vs. $189 \mathrm{kcal}, p=0.01$, ES = 0.48; Figure 4).

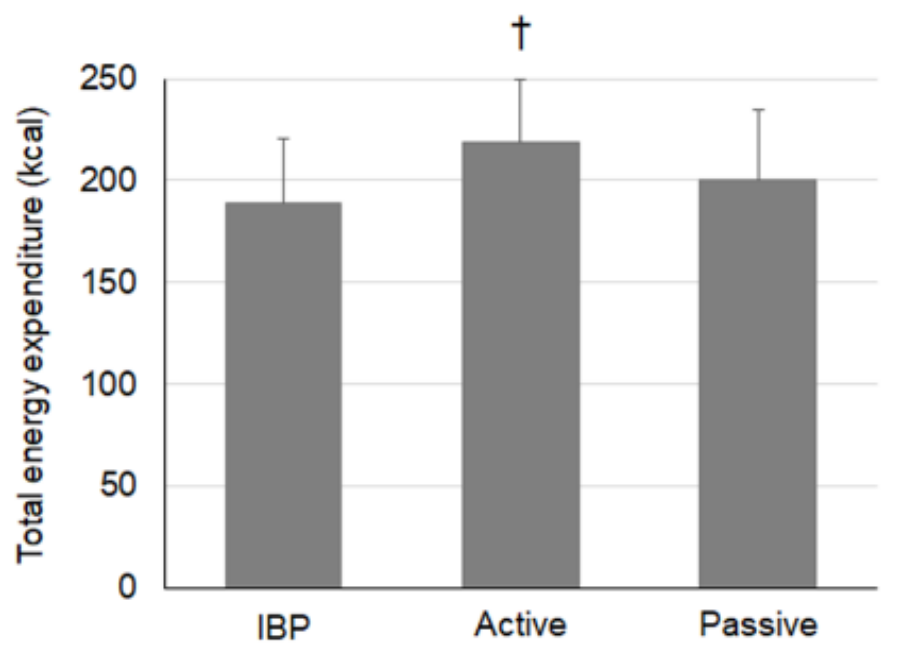

Figure 4. Changes in total energy expenditure regardless of time, IBP: inverted body position; Error bars are upper limits of $95 \%$ confidence intervals, + Condition effect $\left(\mathrm{F}_{2238}=4.81, p=0.01\right)$ : Active was recorded at higher total energy expenditure values compared with the IBP ( 219 vs. $189 \mathrm{kcal}, 14 \%$, $p=0.01, \mathrm{ES}=0.48)$.

Table 1. Changes in heart rate, energy expenditure, blood lactate, and fatigue perception.

\begin{tabular}{|c|c|c|c|c|c|c|c|}
\hline $\begin{array}{c}\text { Mean } \\
(95 \% \text { CIs) }\end{array}$ & Condition & Pre-Run & $\begin{array}{l}\text { Post-Run } \\
0 \text { Min }\end{array}$ & $\begin{array}{l}\text { Post-Run } \\
5 \text { Min }\end{array}$ & $\begin{array}{l}\text { Post-Run } \\
10 \mathrm{Min}\end{array}$ & $\begin{array}{l}\text { Post-Run } \\
20 \mathrm{Min}\end{array}$ & $\begin{array}{l}\text { Post-Run } \\
30 \text { Min }\end{array}$ \\
\hline \multirow{4}{*}{$\begin{array}{l}\text { Blood lactate } \\
\text { (mmol/L) } \\
\text { ICC: } 0.75\end{array}$} & IBP & $\begin{array}{l}1.3 \\
(0.2)\end{array}$ & $\begin{array}{c}9.8 \\
(1.1)\end{array}$ & $\begin{array}{c}6.7 \\
(1.2)\end{array}$ & $\begin{array}{c}5.4 \\
(1.1)\end{array}$ & $\begin{array}{c}4.2 \\
(0.8)\end{array}$ & $\begin{array}{c}3.3 \\
(0.5)\end{array}$ \\
\hline & \multirow{2}{*}{ Active } & 1.3 & 9.4 & 6.9 & 4.4 & 3.3 & 2.7 \\
\hline & & $(0.2)$ & (1.0) & (1.1) & $(0.8)$ & $(0.6)$ & $(0.4)$ \\
\hline & Passive & $\begin{array}{c}1.3 \\
(0.3)\end{array}$ & $\begin{array}{c}9.3 \\
(1.2)\end{array}$ & $\begin{array}{l}8.6 \dagger \\
(1.2)\end{array}$ & $\begin{array}{l}6.0 \ddagger \\
(0.9)\end{array}$ & $\begin{array}{c}4.3 \\
(0.7)\end{array}$ & $\begin{array}{c}3.5 \\
(0.5)\end{array}$ \\
\hline \multirow{5}{*}{$\begin{array}{l}\text { Heart rate }(\mathrm{bpm}) \\
\text { ICC: } 0.91\end{array}$} & IBP & 72.3 & 185.0 & 95.9 & 110.2 & 95.3 & 90.1 \\
\hline & \multirow[b]{2}{*}{ Active } & $\begin{array}{l}(6.2) \\
738\end{array}$ & $\begin{array}{l}(2.0) \\
184.9\end{array}$ & $\begin{array}{l}(5.7) \\
\text { (23.3. }\end{array}$ & $\begin{array}{l}(7.6) \\
1179\end{array}$ & (6.9) & (5.1) \\
\hline & & $\begin{array}{l}73.8 \\
(5.2)\end{array}$ & $\begin{array}{l}184.9 \\
(1.5)\end{array}$ & $\begin{array}{c}123.3 \text { \# } \\
(5.3)\end{array}$ & $(8.2)$ & $\begin{array}{l}96.3 \\
(4.8)\end{array}$ & $\begin{array}{l}91.1 \\
(5.0)\end{array}$ \\
\hline & \multirow{2}{*}{ Passive } & 72.8 & 185.5 & 102.9 & 114.0 & 94.2 & 90.9 \\
\hline & & (5.8) & (1.1) & (5.5) & (7.3) & (5.4) & (4.9) \\
\hline \multirow{6}{*}{$\begin{array}{c}\text { Energy } \\
\text { expenditure (kcal) } \\
\text { ICC: N/A }\end{array}$} & \multirow{2}{*}{ IBP } & \multirow[b]{2}{*}{ - } & 74.5 & 20.5 & 29.9 & 33.2 & 30.6 \\
\hline & & & (10.9) & (4.6) & (7.1) & (7.9) & (6.8) \\
\hline & \multirow{2}{*}{ Active } & \multirow[b]{2}{*}{ - } & 76.3 & 38.8 & 34.1 & 37.3 & 31.9 \\
\hline & & & (12.5) & (5.1) & (6.2) & (8.1) & (7.1) \\
\hline & \multirow{2}{*}{ Passive } & \multirow{2}{*}{ - } & 75.7 & 24.7 & 31.9 & 36.0 & 31.9 \\
\hline & & & (12.0) & (5.5) & (6.5) & (8.0) & (7.3) \\
\hline \multirow{6}{*}{$\begin{array}{c}\text { Fatigue } \\
\text { perception }(\mathrm{cm}) \\
\text { ICC: } 0.76\end{array}$} & \multirow{2}{*}{ IBP } & 1.1 & 6.8 & 3.4 & 2.1 & 1.3 & 0.8 \\
\hline & & $(0.4)$ & $(0.8)$ & $(0.9)$ & (0.5) & $(0.4)$ & $(0.2)$ \\
\hline & \multirow{2}{*}{ Active } & 0.7 & 6.6 & 3.3 & 1.9 & 1.2 & 0.7 \\
\hline & & $(0.2)$ & (0.9) & (0.7) & (0.5) & (0.4) & $(0.2)$ \\
\hline & \multirow{2}{*}{ Passive } & 0.9 & 7.0 & 3.3 & 2.2 & 1.2 & 0.8 \\
\hline & & (0.3) & (0.9) & $(0.6)$ & $(0.8)$ & $(0.4)$ & $(0.4)$ \\
\hline
\end{tabular}

IBP: inverted body position; ICC: intraclass correlation coefficient, + Different from the IBP $(23 \%, p=0.001, \mathrm{ES}=0.82)$ and active $(20 \%, p=0.01, \mathrm{ES}=0.75)$ conditions at post-run $5 \mathrm{~min} ; \ddagger$ Different from the active condition $(27 \%$, $p=0.02, \mathrm{ES}=0.90)$ at post-run $10 \mathrm{~min}$; \# Different from the IBP $(22 \%, p<0.0001, \mathrm{ES} 2.52)$ and passive $(17 \%, p=0.002$, $\mathrm{ES}=1.92)$ conditions at post-run $5 \mathrm{~min}$. 
Fatigue perception did not differ among the three cool-down conditions at each time point (no condition $\times$ time interaction: $\mathrm{F}_{10,238}=0.13, p=0.99$; no condition effect: $\mathrm{F}_{2,238}=0.87, p=0.42$; time effect: $\mathrm{F}_{5,238}=$ $245.80, p<0.0001$; Table 1). Regardless of the condition, fatigue perception was $87 \%$ higher after running $(6.8 \mathrm{~cm}, p<0.0001$, ES $=4.63)$ and returned to the pre-run level $(0.9 \mathrm{~cm})$ at post-run $20 \mathrm{~min}(1.2 \mathrm{~cm}, p=0.55$; Figure $3 \mathrm{~A})$.

The circumference of the left (no condition $\times$ time interaction: $\mathrm{F}_{10,238}=0.28, p=0.99$; condition effect: $\mathrm{F}_{2,238}=3.72, p=0.03$; time effect: $\mathrm{F}_{5,238}=3.88, p=0.002$; Table 2) and right (no condition $\times$ time interaction: $\mathrm{F}_{10,238}=0.25, p=0.99$; no condition effect: $\mathrm{F}_{2,238}=1.26, p=0.29$; time effect: $\mathrm{F}_{5,238}=6.66$, $p<0.0001$; Table 2) thighs, and left (no condition $\times$ time interaction: $\mathrm{F}_{10,238}=0.96, p=0.48$; condition effect: $\mathrm{F}_{2,238}=22.32, p<0.0001$; time effect: $\mathrm{F}_{5,238}=41.33, p<0.0001$ ) and right (no condition $\times$ time interaction: $\mathrm{F}_{10,238}=0.79, p=0.64$; condition effect: $\mathrm{F}_{2,238}=12.13, p<0.0001$; time effect: $\mathrm{F}_{5,238}=44.57$, $p<0.0001)$ calves did not differ between the conditions at each time point.

Blood lactate was highly correlated with fatigue perception $(\mathrm{r}=0.75, p<0.0001$; Figure 3B).

Good to excellent measurement consistency (ICC values from 0.75 to 0.99 ; Tables 1 and 2) was calculated for all measurements [30].

Table 2. Changes in circumference of lower-extremities.

\begin{tabular}{|c|c|c|c|c|c|c|c|}
\hline $\begin{array}{c}\text { Mean } \\
(95 \% \text { CIs })\end{array}$ & Condition & Pre-Run & $\begin{array}{l}\text { Post-Run } \\
0 \text { Min }\end{array}$ & $\begin{array}{l}\text { Post-Run } \\
5 \text { Min }\end{array}$ & $\begin{array}{l}\text { Post-Run } \\
10 \text { Min }\end{array}$ & $\begin{array}{l}\text { Post-Run } \\
20 \text { Min }\end{array}$ & $\begin{array}{c}\text { Post-Run } \\
30 \mathrm{Min}\end{array}$ \\
\hline \multirow{5}{*}{$\begin{array}{l}\text { Left thigh }(\mathrm{cm}) \\
\text { ICC: } 0.99\end{array}$} & IBP & $\begin{array}{l}54.4 \\
(1.2)\end{array}$ & $\begin{array}{l}54.7 \\
(1.2)\end{array}$ & $\begin{array}{l}54.5 \\
(1.2)\end{array}$ & $\begin{array}{l}54.4 \\
(1.2)\end{array}$ & $\begin{array}{l}54.4 \\
(1.2)\end{array}$ & $\begin{array}{l}54.4 \\
(1.2)\end{array}$ \\
\hline & \multirow{2}{*}{ Active } & 54.2 & 54.6 & 54.4 & 54.3 & 54.3 & 54.3 \\
\hline & & (1.4) & (1.4) & (1.4) & (1.4) & (1.4) & (1.4) \\
\hline & \multirow{2}{*}{ Passive } & 54.4 & 54.7 & 54.7 & 54.5 & 54.4 & 54.4 \\
\hline & & (1.4) & (1.4) & (1.5) & (1.4) & (1.4) & (1.4) \\
\hline \multirow{6}{*}{$\begin{array}{l}\text { Right thigh }(\mathrm{cm}) \\
\text { ICC: } 0.99\end{array}$} & \multirow{2}{*}{ IBP } & 54.6 & 54.9 & 54.6 & 54.6 & 54.6 & 54.5 \\
\hline & & (1.1) & (1.2) & (1.2) & (1.2) & (1.1) & (1.1) \\
\hline & \multirow{2}{*}{ Active } & 54.4 & 55.0 & 54.7 & 54.6 & 54.5 & 54.5 \\
\hline & & (1.3) & (1.4) & (1.2) & (1.3) & (1.3) & (1.3) \\
\hline & \multirow{2}{*}{ Passive } & 54.5 & 54.9 & 54.8 & 54.8 & 54.7 & 54.6 \\
\hline & & (1.3) & (1.3) & (1.3) & (1.3) & (1.3) & (1.3) \\
\hline \multirow{6}{*}{$\begin{array}{l}\text { Left calf }(\mathrm{cm}) \\
\text { ICC: } 0.99\end{array}$} & \multirow{2}{*}{ IBP } & 36.3 & 36.9 & 36.6 & 36.5 & 36.4 & 36.4 \\
\hline & & (0.9) & (1.0) & (0.9) & (0.9) & (0.9) & (0.9) \\
\hline & \multirow{2}{*}{ Active } & 36.4 & 37.0 & 36.9 & 36.7 & 36.6 & 36.6 \\
\hline & & (1.1) & (1.1) & (1.1) & (1.1) & (1.1) & (1.1) \\
\hline & \multirow{2}{*}{ Passive } & 36.4 & 37.0 & 36.9 & 36.7 & 36.7 & 36.6 \\
\hline & & (1.0) & (1.0) & (1.0) & (1.0) & (1.0) & (1.0) \\
\hline \multirow{6}{*}{$\begin{array}{l}\text { Right calf }(\mathrm{cm}) \\
\text { ICC: } 0.99\end{array}$} & \multirow{2}{*}{ IBP } & 36.5 & 37.2 & 36.9 & 36.7 & 36.6 & 36.6 \\
\hline & & $(0.9)$ & $(0.9)$ & $(0.9)$ & (0.9) & (0.9) & $(0.9)$ \\
\hline & \multirow{2}{*}{ Active } & 36.5 & 37.2 & 37.0 & 36.8 & 36.7 & 36.7 \\
\hline & & (1.0) & (1.0) & (1.0) & (1.0) & (1.0) & (1.0) \\
\hline & \multirow{2}{*}{ Passive } & 36.6 & 37.2 & 37.1 & 36.9 & 36.9 & 36.8 \\
\hline & & $(0.9)$ & (1.0) & (1.0) & (1.0) & (1.0) & (1.0) \\
\hline
\end{tabular}

IBP: inverted body position; ICC: intraclass correlation coefficient, No condition $\times$ time interactions in circumference of left $\left(\mathrm{F}_{10,238}=0.28, p=0.99\right)$ and right $\left(\mathrm{F}_{10,238}=0.25, p=0.99\right)$ thigh, and circumference of left $\left(\mathrm{F}_{10,238}=0.96\right.$, $p=0.48)$ and right $\left(\mathrm{F}_{10,238}=0.79, p=0.64\right)$ calf.

\section{Discussion}

The purpose of this study was to examine how the IBP condition consisting of continuous alternation between 30-s IBP and a supine position for $5 \mathrm{~min}$ would help physiological and psychological recovery after intense running relative to active (walking) and passive (sitting) recovery methods. While walking is a commonly recommended method $[10,31]$ and sitting is considered as a control, we were interested in comparing these existing and frequently practiced methods to a recovery condition containing IBP. During the initial $5 \mathrm{~min}$ of the recovery period, the IBP was effective in reducing the 
blood lactate and heart rate to levels similar to the active and passive conditions. In other words, the IBP condition produced an effect similar to that of the active condition in blood lactate with less energy expenditure. This observation suggests that the recovery condition including IBP could be an alternative recovery strategy after a short bout of intense exercise. Since blood lactate removal is dependent on the amount of blood flow to working muscles, and the process is facilitated by muscle contraction [17], performing IBP could be beneficial for individuals who need a fast recovery while minimizing energy consumption.

The IBP and active (walking at a speed of 5 to $6 \mathrm{~km} / \mathrm{h}$ ) strategies in this study reduced blood lactate by $32 \%(9.8$ to $6.7 \mathrm{mmol} / \mathrm{L})$ and $27 \%(9.4$ to $6.9 \mathrm{mmol} / \mathrm{L})$, respectively, at $5 \mathrm{~min}$ postexercise (post-run $0 \mathrm{~min}$ ). The effects of recovery strategies with active movements [10,31,32], electrotherapy [33], and massage [31] were previously reported. Comparable corresponding values at similar time points in other studies included a $19 \%(14.9$ to $12.0 \mathrm{mmol} / \mathrm{L})$ reduction with a 5 -min treadmill run $($ at $50 \%$ of maximal speed) [32] and a $49 \%$ (3.9 to $2.0 \mathrm{mmol} / \mathrm{L})$ reduction with 6 min of motor level electrotherapy (at 9, 8, and $7 \mathrm{~Hz}$ for $2 \mathrm{~min}$ each via 8 electrodes) [33]. At $10 \mathrm{~min}$ postexercise (after subjects had finished a 5-min static stretch in our study), blood lactate was reduced by $45 \%$ (9.8 to $5.4 \mathrm{mmol} / \mathrm{L}$ ) and $53 \%(9.4$ to $4.4 \mathrm{mmol} / \mathrm{L})$ in the IBP and active conditions, respectively. Other studies reported reductions of $40 \%$ (14.9 to $8.9 \mathrm{mmol} / \mathrm{L}$ ) with a 10-min treadmill run (at $50 \%$ of the maximal speed) [32], $51 \%(11.7$ to $5.7 \mathrm{mmol} / \mathrm{L}$ ) with a 10-min free style swim (at 65\% of each individual's best $200-\mathrm{m}$ front crawl swim velocity) [31], and 39\% (11.6 to $7.1 \mathrm{mmol} / \mathrm{L}$ ) with a 10-min massage (using the effleurage, petrissage, tapotement, and compression techniques) [31]. As indicated by these indirect comparisons at 5 and 10 min postexercise, our IBP condition (a combination of the 5-min IBP and static stretch) appears to be as effective as other recovery activities. Although not directly measured, we believe that the effect of the IBP could have been attributed to hemodynamic changes similar to those of using compression garments [34,35]. According to men's and women's Taekwondo Kyorugi schedules at the Olympic Games in Rio in 2016, the rests between matches ranged from 360 min to less than $60 \mathrm{~min}$. In the Asian Games in Jakarta-Palembang in 2018, the rest times in the men's fencing épée ranged from $80 \mathrm{~min}$ to $175 \mathrm{~min}$. During such short time periods, a recovery activity enhancing a rapid blood lactate removal with minimal energy expenditure would contribute to the performance in the subsequent match. Because all of the comparable recovery strategies reported require an electrical device [33], massage personnel [31], or to expend more energy [31,32], our method with IBP could be the best option. Although the blood lactate values in the three conditions in our study became similar at $20 \mathrm{~min}$ postexercise, IBP is still beneficial because it resulted in a longer time to rest with a low blood lactate level.

Fatigue perception did not differ among the three recovery conditions at each time point. Previously, electrotherapy (motor level stimulation via 8 electrodes) and the passive (sitting on a chair) recovery method reduced perceived exertion by $46 \%$ and $38 \%$ compared with active recovery, respectively [33]. Another study [32] reported 18\% less perceived exertion with passive (sitting on a chair) recovery than with active (treadmill run at 50\% maximal speed) recovery [32]. Although the results of the Borg scales (0 to 10 points: [33]; 6-20 points: [32]) are comparable to our fatigue perception because both are measures of subjective physical condition, the differences of the measurement characteristics could explain why there was no difference across the conditions in our study. The Borg scale matches a numeric scale with descriptions of exertion, asking subjects to indicate their exertion level, whereas our measurement simply asked subjects to place themselves between "unfatigued" and "fatigued" on a visual analogue scale. Measurements were also taken during exercise using the Borg scale and after exercise in our study. Since subjects in previous studies felt less exertion in the passive condition than those in the active condition [32,33], providing different descriptions (e.g., fresh or recovered) or using a more detailed numeric scale may have produced a different result. Interestingly, blood lactate and fatigue perception values had a strong correlation in our study $\left(r=0.75, r^{2}=0.57\right)$. Thus, at least $57 \%$ of an individual's perceived fatigue can be explained by blood lactate and vice versa. However, fatigue perception returned to the pre-run level at $20 \mathrm{~min}$ postexercise (post-run $20 \mathrm{~min}$ ) 
whereas blood lactate levels did not. This observation has several practical implications. First, people may feel complete recovery although their bodies are still in the process of physiological recovery. Second, a complete physiological recovery may be unnecessary for psychological (perceptual) recovery. Third, in addition to blood lactate, there could be other factors which contribute to the level of fatigue perception. A future study should examine the relationships between psychological, physiological, and athletic performance.

Similarly, there were no changes in the circumferences of lower extremities at any time point. Given that a tape measure was used to obtain circumferences in many previous studies [34-37], the measurement reproducibility in our study was strong (ICC value of 0.99 for between-session reliability in all measurements), measurement technique or errors were unlikely to contribute to the results. In fact, we did not even observe a circumference change at the post-run measurements, which could be explained by the exercise duration and mode (specific energy system). Previously reported postexercise extremity circumference was induced by resistance [34,35] or endurance exercise [36,37]. Therefore, an approximately 7-min all-out treadmill run may not have been sufficient to increase leg swelling. Exercise-induced transient hypertrophy, also known as "the pump", is thought to be caused by the accumulation of intracellular fluid from reactive hyperemia [38] or osmolytic activity [39]. In endurance activities, the expansion of extracellular volume [37] due to increased plasma volume and sodium retention [40] is thought to be responsible for oedematous swelling. While we assumed that our intense treadmill run mostly used the combined energy system of anaerobic glycolysis, it produced neither of the physiological mechanisms, resulting in no circumference change. Because body fluid removal is an important facet of physical recovery, a future investigation should examine how the IBP strategy affects the increased circumference caused by either resistance or prolonged endurance exercise. Appendicular body composition analysis along with skinfold thickness would provide better accuracy in the assessment of exercise-induced anthropometric changes.

There are several limitations and assumptions in our study that may benefit future research. Although good criterion-related validity and high reliability in the estimation of energy expenditure using the same heart rate monitoring device were established [41], the major contributing factors such as the physical activity and sedentary levels [42], and percentage of body fat [43] were not reflected. Additionally, a lower heart rate recorded during the IBP might have underestimated the whole-body metabolism and energy consumption. Therefore, we acknowledge the level of accuracy in estimating energy expenditure as a limitation. While accepted, our hypothesis was based on increased blood flow for a body position with $15^{\circ}$ head-down tilt [21-23] and the lack of direct measures on blood flow parameters limit us to explain and interpret the observed benefits. As an elevated blood pressure during and after exercise is typical, performing IBP immediately after exercise may be harmful by applying additional pressure to blood vessels. When comparing the inversion duration $\left(90^{\circ}\right.$ for $\left.2 \mathrm{~min}\right)$ in previous reports $[44,45]$ to ours $\left(90^{\circ}\right.$ for $13 \mathrm{~s}$ : Figure 2$)$, we assume that the possibility of additional blood pressure was minimal. Additionally, our subjects' heart rate at the last minute of the treadmill run and the beginning of IBP were 183 and $121 \mathrm{bpm}$, respectively. A 2-min interval for the post-run measurements resulted in a $34 \%$ reduction in heart rate (183 to $121 \mathrm{bpm})$. Considering that both heart rate and blood pressure are linearly related to exercise intensity [46], a reduced heart rate value indirectly supports the idea that our subjects performing IBP were not in a deleterious situation. However, future studies should attempt to compare the change of blood flow volume and pressure during the recovery period to resolve our limitations. Lastly, the contraindications of IBP should be addressed since the IBP may be unsafe for pregnant individuals or those with abnormal blood pressure or other cardiovascular diseases, eye or ear injuries, or herniated discs.

According to our data, a 10-min recovery strategy consisting of $5 \mathrm{~min}$ of IBP and a 5-min static stretch was the most effective of the tested protocols in removing blood lactate and minimizing energy expenditure during the acute recovery period (the first $30 \mathrm{~min}$, postexercise). Therefore, the recovery condition including our IBP protocol is an appropriate strategy to enhance physical and psychological recovery. We particularly recommend this IBP protocol for athletes who complete several matches 
(events) within a few hours on a single day (e.g., tournaments for Taekwondo, Judo, weightlifting, fencing, wrestling, sprint cycling, and swimming). In the final stage of matches (e.g., after quarterfinals), the fatigue level would be high. In this situation, physical fitness and stamina can play bigger roles than technical and tactical strategies. Therefore, we recommend practicing our IBP method between matches. If an IBP device is unavailable, peer-assisted IBP or a supine position with legs elevated against a wall could be used instead.

Author Contributions: Conceptualization, M.S.K. and J.P. Methodology, J.P. Formal analysis, M.S.K. and J.P. Investigation, J.P. Data curation, M.S.K. Writing — original draft preparation, M.S.K. and J.P. Writing —review and editing, J.P. Supervision, J.P. Project administration, J.P. All authors have read and agreed to the published version of the manuscript.

Funding: This research received no external funding.

Acknowledgments: This study received no specific grant from any funding agency. We thank Chae Rin Kim, Chaerin Yeom, and Gihum Kown for their data collection and reduction.

Conflicts of Interest: The authors declare no conflict of interest.

\section{References}

1. Ramírez-Campillo, R.; Henríquez-Olguín, C.; Burgos, C.; Andrade, D.C. Effect of progressive volume-based overload during plyometric training on explosive and endurance performance in young soccer players. J. Strength Cond. Res. 2015, 29, 1884-1893. [CrossRef]

2. Fry, A.; Mullinger, K.J.; O'Neill, G.C.; Mullinger, K.J.; Brookers, M.J. The effect of physical fatigue on oscillatory dynamics of the sensorimotor cortex. Acta Physiol. 2017, 220, 370-381. [CrossRef] [PubMed]

3. Meeusen, R.; Duclos, M.; Gleespn, M.; Foster, C.; Fry, A.; Gleeson, M.; Nieman, D.; Raglin, J.; Rietjens, G.; Steinacker, J.; et al. Prevention, diagnosis and treatment of the overtraining syndrome. Eur. J. Appl. Physiol. 2006, 6, 1-14. [CrossRef]

4. Halson, S.; Jeukendrup, A.E. Does overtraining exist? An analysis of overreaching and overtraining research. Sports Med. 2004, 34, 967-981. [CrossRef] [PubMed]

5. Thiel, C.; Vogt, L.; Bürklein, M.; Rosenhagen, A. Functional overreaching during preparation training of elite tennis professionals. J. Hum. Kinet. 2011, 28, 79-89. [CrossRef] [PubMed]

6. Hausswirth, C.; Mujika, I. Recovery for Performance in Sport; Human Kinetics: Champain, France, 2012.

7. Belcastro, A.N.; Bonen, A. Lactic acid removal rates during controlled and uncontrolled recovery exercise. J. Appl. Physiol. 1975, 39, 932-936. [CrossRef]

8. Dupont, G.; Moalla, W.; Guinhouya, C.; Ahmadi, S. Passive versus active recovery during high-intensity intermittent exercises. Med. Sci. Sports Exerc. 2004, 36, 302-308. [CrossRef]

9. Menzies, P.; Menzies, C.; Mclntyre, L.; Paterson, P. Blood lactate clearance during active recovery after an intense running bout depends on the intensity of the active recovery. J. Sports Sci. 2010, 28, 975-982. [CrossRef]

10. Mota, M.R.; Dantas, R.A.E.; Oliveira-Silva, I.; Mahalhaes Sales, M.; da Costa Sotero, R.; Espiodola Mota Venancio, P.; Teixeira Junior, J.; Nobre Chaves, S.; de Lima, F.D. Effect of self-paced active recovery and passive recovery on blood lactate removal following a $200 \mathrm{~m}$ freestyle swimming trial. Open Access J. Sports Med. 2017, 8, 155-160. [CrossRef]

11. Soares, A.H.; Oliveira, T.P.; Cavalcante, B.R.; Farah, B.Q.; Lima, A.; Cucato, G.G.; Cardoso, C.G.; Ritti-Dias, R.M. Effects of active recovery on autonomic and haemodynamic responses after aerobic exercise. Clin. Physiol. Funct. Imaging 2017, 37, 62-67. [CrossRef]

12. Fairchild, T.J.; Armstrong, A.A.; Rao, A.; Hawk, L. Glycogen synthesis in muscle fibers during active recovery from intense exercise. Med. Sci. Sports Exerc. 2003, 35, 595-602. [CrossRef] [PubMed]

13. Baquet, G.; Dupont, G.; Gamelin, F.-X.; Aucountier, J.; Berthoin, S. Active versus passive recovery in high-intensity intermittent exercises in children: An exploratory study. Pediatr. Exerc. Sci. 2019, 31, 248-253. [CrossRef] [PubMed]

14. Toubekis, A.G.; Douda, H.T.; Tokmakidis, S.P. Influence of different rest intervals during active or passive recovery on repeated sprint swimming performance. Eur. J. Appl. Physiol. 2005, 93, 694-700. [CrossRef] 
15. Monedero, J.; Donne, B. Effect of recovery interventions on lactate removal and subsequent performance. Int. J. Sports Med. 2000, 21, 593-597. [CrossRef]

16. Draper, N.; Bird, E.L.; Coleman, I.; Hodgson, C. Effects of active recovery on lactate concentration, heart rate and RPE in climbing. J. Sports Sci. Med. 2006, 5, 97-105. [PubMed]

17. Gladden, L.B. Muscle as a consumer of lactate. Med. Sci. Sport Exer. 2000, 32, 764-771. [CrossRef] [PubMed]

18. Starkey, C. Therapeutic Modalities; FA Davis Company: Philadelphia, PA, USA, 2013.

19. Maestrini, D. Genesis of the so-called insufficient contractions of the heart in decompensation. Policlin. Prat. 1951, 58, 257-268.

20. Brooks, G.A.; Fahey, T.D.; Baldwin, K.M. Exercise Physiology: Human Bioenergenetics and Its Applications; McGraw Hill: New York, NY, USA, 2005; pp. 293-308.

21. McInnis, N.H.; Journeay, W.S.; Jay, O.; Lelair, E.; Kenny, G.P. $15^{\circ}$ Head-down tilt attenuates the postexercise reduction in cutaneous vascular conductance and sweating and decreases esophageal temperature recovery time. J. Appl. Physiol. 2006, 101, 840-847. [CrossRef]

22. Journeay, W.S.; Jay, O.; McInnis, N.H.; Lelair, E.; Kenny, G.P. Postexercise heat loss and hemodynamic responses during head-down tilt are similar between genders. Med. Sci. Sports Exerc. 2007, 39, 1308-1804. [CrossRef]

23. Siamwala, J.H.; Lee, P.C.; Macias, B.R.; Hargens, A.R. Lower-body negative pressure restores leg bone microvascular flow to supine levels during head-down tilt. J. Appl. Physiol. 2015, 119, 101-109. [CrossRef]

24. Karvonen, J.; Vuorimaa, T. Heart rate and exercise intensity during sports activities. Sports Med. 1988, 5, 303-311. [CrossRef] [PubMed]

25. Smith, D.M.; McAuliffe, J.; Johnson, M.J.; Button, D.C. Seated inversion adversely affects vigilance tasks and suppresses heart rate and blood pressure. Occup. Ergon. 2013, 11, 153-163. [CrossRef]

26. Hart, S.; Drevets, K.; Alford, M.; Salacinski, A.; Hunt, B.E. A method-comparison study regarding the validity and reliability of the Lactate Plus analyzer. BMJ Open 2013, 3, e001899. [CrossRef]

27. Shahid, A.; Wilkinson, K.; Marcu, S.; Shapiro, C.M. Visual analogue scale to evaluate fatigue severity (VAS-F.). In STOP, THAT and One Hundred Other Sleep Scales; Spinger: New York, NY, USA, 2011; pp. 399-402.

28. Wolfe, F. Fatigue assessments in rheumatoid arthritis: Comparative performance of visual analog scales and longer fatigue questionnaires in 7760 patients. J. Rheumatol. 2004, 31, 1896-1902. [PubMed]

29. Cohen, J. A power primer. Psychol. Bull. 1992, 112, 155. [CrossRef]

30. Koo, T.K.; Li, M.Y. A guideline of seletcing and reporting intraclass correlation coefficients for reliability research. J. Chripract. Med. 2016, 15, 155-163.

31. Ali Rasooli, S.; Koushkie Jahromi, M.; Asadmanesh, A.; Salesi, M. Influence of massage, active and passive recovery on swimming performance and blood lactate. J. Sport Med. Phys. Fit. 2012, 52, 122-127.

32. Ouergui, I.; Hammouda, O.; Chtourou, H.; Gmada, N.; Franchini, E. Effects of recovery type after a kickboxing match on blood lactate and performance in anaerobic tests. Asian J. Sports Med. 2014, 5, 99-107.

33. Warren, C.D.; Szymanski, D.J.; Landers, M.R. Effects of three recovery protocols on range of motion, heart rate, rating of perceived exertion, and blood lactate in baseball pitchers during a simulated game. J. Strength Cond. Res. 2015, 29, 3016-3025. [CrossRef]

34. Goto, K.; Morishima, T. Compression garment promotes muscular strength recovery after resistance exercise. Med. Sci. Sports Exerc. 2014, 46, 2265-2270. [CrossRef]

35. Kraemer, W.J.; Flanagan, S.D.; Comstock, B.A.; Fragala, M.; Earp, J.; Dunn-Lewis, C.; Ho, J.; Thomas, G.; Solomon-Hill, G.; Penwell, Z.; et al. Effects of a whole body compression garment on markers of recovery after a heavy resistance workout in men and women. J. Strength Cond. Res. 2010, 24, 804-814. [CrossRef]

36. Dawson, L.G.; Dawson, K.A.; Tiidus, P.M. Evaluating the influence of massage on leg strength, swelling, and pain following a half-marathon. J. Sport Scimed. 2004, 3, 37-43.

37. Knechtle, B.; Vinzent, T.; Kirby, S.; Knechtle, P. The recovery phase following a triple iron triathlon. J. Hum. Kinet. 2009, 21, 65-74. [CrossRef]

38. Schoenfeld, B.J.; Contreras, B. The pump: Potential mechanisms and applications for enhancing hypertrophic adaptations. Strength Cond. J. 2014, 36, 21-25. [CrossRef]

39. Schoenfeld, B.J. The mecahnisms of muscle hypertrophy and their application to resistance training. J. Strength Cond. Res. 2010, 24, 2857-2872. [CrossRef] 
40. Fellmann, N.; Bedu, M.; Giry, J.; Pharmakis-amadieu, M.; Bezou, M.; Barlet, J.; Coudert, J. Hormonal, fluid, and electrolyte changes during a 72-h recovery from a 24-h endurance run. Int. J. Sports Med. 1989, 10, 406-412. [CrossRef]

41. Engström, E.; Ottosson, E.; Wohlfart, B.; Grundstorm, N.; Wisen, A. Comparison of heart rate measured by Polar RS400 and ECG, validity and repeatability. Adv. Physiother. 2012, 14, 115-122. [CrossRef]

42. Besson, H.; Brage, S.; Jakes, R.W.; Ekelund, U.; Wareham, N. Estimating physical activity energy expenditure, sedentary time, and physical activity intensity by self-report in adults. Am. J. Clin. Nutr. 2010, 91, 106-114. [CrossRef]

43. Irwin, M.L.; Ainsworth, B.E.; Conway, J.M. Estimation of energy expenditure from physical activity measures: Determinants of accuracy. Obes. Res. 2001, 9, 517-525. [CrossRef]

44. Haskvitz, E.M.; Hanten, W.P. Blood pressure response to inversion traction. Phys. Ther. 1986, 66, 1361-1364. [CrossRef]

45. LeMarr, J.D.; Golding, L.A.; Crehan, K.D. Cardiorespiratory responses to inversion. Physician Sportsmed. 1983, 11, 51-57. [CrossRef]

46. Cornelissen, V.A.; Verheyden, B.; Aubert, A.E.; Fagard, R.H. Effects of aerobic training intensity on resting, exercise and post-exercise blood pressure, heart rate and heart-rate variability. J. Hum. Hypertens. 2010, 24, 175-182. [CrossRef]

(C) 2020 by the authors. Licensee MDPI, Basel, Switzerland. This article is an open access article distributed under the terms and conditions of the Creative Commons Attribution (CC BY) license (http://creativecommons.org/licenses/by/4.0/). 